\title{
Recruitment of African Americans into Cancer Clinical Research: Strategies and Outcomes
}

\author{
Vanessa B. Sheppard • Arnethea Sutton • Esther Holmes • Megan Edmonds • Michael \\ A. Preston • Asmaa M. Namoos $(\mathbb{D} \cdot$ Matthew Wells $\cdot$ Maria D. Thomson
}

Accepted: 14 June 2021 / Published online: 9 August 2021

(C) The New York Academy of Medicine 2021

\begin{abstract}
This study utilized data from four cancerfocused research studies that recruited and retained African Americans. Strategies and outcomes across four cancer prevention and control studies were analyzed. Descriptive statistics were used to display participant characteristics. There were 712 African American (Black) participants of which $14.6 \%$ were males. Common strategies involved connecting with community stakeholders and identifying study champions. Study recruitment methods might not be generalizable to all populations of African Americans due to geographic locations, study protocols (e.g., risk reduction), target populations (i.e., eligibility criteria), and available resources. Many African Americans have a strong interest in cancer-related research as demonstrated by participation levels. Teams that connect with relevant stakeholders and include diverse teams may be useful to engage larger numbers of minorities in cancer control research to impact morbidity and mortality.
\end{abstract}

Keywords Cancer disparties - American African . Clinical research $\cdot$ Clinical trial $\cdot$ Breast cancer $\cdot$ Prostate cancer

\footnotetext{
V. B. Sheppard - A. Sutton · E. Holmes - M. Edmonds •

M. A. Preston - A. M. Namoos $(\bowtie) \cdot$ M. Wells •

M. D. Thomson

Department of Health Behavior and Policy, Office of Health

Equity \& Disparities Research, Virginia Commonwealth

University, 830 East Main Street, PO Box 980149, Richmond, VA

23298-0149, USA

e-mail: Asmaa.Namoos@vcuhealth.org
}

\section{Introduction}

Cancer is the second leading cause of death among African Americans, and African Americans have the highest mortality rate for most cancers compared with other racial and ethnic groups [1]. Cancer clinical research studies are needed to evaluate strategies to prevent cancer, initiate treatment for cancer, and improve the effectiveness of treatment methods for cancer among African Americans. However, African Americans are widely underrepresented in cancer clinical research. Therefore, there is a strong need to recruit African Americans into cancer clinical research studies to generalize study results to this population and develop solutions to reduce related cancer health disparities.

Many barriers have been identified that contribute to underrepresentation of African Americans in clinical research. Patient-related barriers include informational, attitudinal, and practical factors. Informational barriers include knowledge of the study [2,3], potential negative side effects, and invasiveness of procedures [4]. Attitudinal factors include fear, suspicion, and mistrust of researchers $[2,3,5,6]$. Practical factors include the need for transportation, financial concerns, and interference with work and family responsibilities [2, 4].

A number of strategies have been identified to address barriers to enrollment in clinical research, promoting inclusion and greater representation of African Americans. In one model created to address mentioned barriers, a streamlined process between research staff and the patients' physician made it possible for the physician to share clinical trial options when discussing 
treatment options with the patient [7]. After learning of the available clinical trials, patients met with the research nurse to review details of the study. This increased patients' awareness of potential studies to join along with the study procedures. In this model, patients were also provided assistance with practical barriers such as transportation and cost, and the research activities were conducted at a location that was accessible and familiar to patients [7].

Additional strategies to increase African Americans' participation in clinical research include conducting the studies within their community, tailoring research material, and ensuring that the research faculty and staff are culturally competent $[8,9]$. Cultural competence, a set of cultural skills, awareness, and knowledge that enable one to work and communicate effectively cross-culturally, increases the trust and partnership between the participants and the research staff, which can increase the participation rate of African Americans in clinical research [9-11]. Strategies utilized to tailor research material to African Americans could include a focus on spirituality, systemic barriers (e.g., racism) to optimal health along with other cultural messages [12].

Despite the recognition of the need to engage African Americans and their high cancer burden, data are lacking on strategies within multiple components of the cancer control continuum specific to this population. Effective recruitment methods are needed to increase participation of African Americans in cancer clinical research. Furthermore, subgroups of African Americans, such as those living in rural areas, are also underrepresented in clinical research and likely have a unique set of barriers and facilitators to participation in clinical research. The purpose of this study is to describe the recruitment methods and participation rate of African Americans across multiple studies and suggest directions for future studies.

\section{Methods and Results}

A total of four studies were conducted to engage African Americans from diverse backgrounds and settings. The purpose, eligibility, and setting for each study are described briefly below.

Study 1: Narrowing Gaps in Adjuvant Therapy Study (GAP) (Sheppard et al.) The purpose of this study was to understand factors that contribute to racial disparities in uptake of adjuvant therapy for breast cancer [13]. Particularly, we were interested in understanding racial differences in adjuvant chemotherapy uptake. Inclusion criteria were (1) invasive non-metastatic breast cancer diagnosis, (2) $\geq 21$ years of age, and (3) eligible to receive systemic therapy (e.g., chemotherapy, endocrine therapy). Women were excluded from this study if they (1) were $>20$ weeks past their definitive surgery, (2) were diagnosed with recurrent or distant metastatic disease, (3) identified as a race other than Black or White, (4) were unable to provide informed consent, and (5) were unable to speak English. Black and White women were eligible for this study; however, given the goal to analytically assess racial differences, we were intentional about oversampling Black women. To participate in this study, women provided their medical records and completed one telephone interview with a trained clinical research assistant. Women were recruited via community settings and clinics in Washington, DC and Detroit, MI.

\section{Study 2: Rural African American Families (Preston} et al.) This study examined rural men's barriers and facilitators to receiving care and to understand their social networks and their role in seeking care. Inclusion criteria were (1) African American male survivor and (2) adult family members of the African American male survivor. Recruitment to this study included collaborations with local community partners for each study site in three southern states. Recruitment partners included community-based organizations, faith-based organizations, local prostate cancer foundation, local cancer coalition, and local workplace. Focus groups were conducted with families who resided in select counties at each study site. Family members included (1) first- and second-degree relatives of the self-identified Black men. Both male and female relatives were eligible.

Study 3: Virginia Living Well Research Registry (Thomson et al.-is there an abstract) Adults over the age of 18 were eligible for this study if they lived in Virginia. The purpose of this community registry was twofold: first, to build research capacity in predominantly rural communities and increase access to clinical and research trials; second, to collect critical longitudinal data about a range of exposures and behaviors that may be influencing cancer risks. The community partner network was leveraged, and community outreach strategies were utilized to oversample rural areas. Participants completed the survey in either a paper and pencil format in-person or as an electronic (e- 
survey) survey with embedded questions to assess participant comprehension. Participants had the option to indicate if they would provide biospecimens (saliva sample) or agree to participate in future research.

Study 4: Y-WE SURVIVE BREAST CANCER (Edmonds, et al., unpublished) The goal of this study was to examine surveillance mammography experiences among breast cancer survivors engaged in social media. Breast cancer survivors were recruited to participate in virtual focus groups or a Qualtrics survey online, using breast cancer focused virtual platforms (e.g., Breastcancer.org, Facebook, Instagram Quora, Reddit). Study ads were developed and targeted to the study population using algorithms within Facebook, Instagram, and Twitter. To be eligible for the study, a screening link was embedded in the ads with the following inclusion criteria: selfidentified as African American/Black or White, diagnosed with breast cancer, $\geq 21$ years old or older and completed definitive surgery (e.g., mastectomy, lumpectomy). To help fill gaps in surveillance research, this study tailored recruitment efforts around Black women in the design and outreach of our study ads. Black breast cancer survivors and advocacy groups helped refine the study advertisements and disseminated ads to their survivor networks and social media followings.

Key features of the descriptive components across studies are depicted in Table 1. A total of 712 participants were recruited across studies. All studies employed community members or stakeholders input on recruitment strategies, and 50\% employed the use of social media. Because two studies centered on breast cancer, there was an overrepresentation of women. Interestingly, two of the four studies oversampled rural participants and included rural Black men, a group historically and presently underrepresented in research.

\section{Discussion}

This paper described various strategies employed to recruit and conduct cancer control research with African Americans. Of note, two of the four studies included African American men, who have the highest incidence and mortality rates for colorectal and prostate cancers [14]. Those studies tended to employ recruitment efforts that included social media and community-engagement approaches. Additionally, investigative teams on these studies included African American males either as investigators or research staff. Reports suggest that having diverse teams that are reflective of the study population is an important consideration (Sheppard, SandersonCos, etc.). Unfortunately, the lack of robust pipeline of Black males often leaves many teams without this priority demographic. Findings are relevant to engagement of African American men, use of emerging technology and social networks, and building strong community partnerships.

Engaging Black men in cancer prevention and control research should be a national priority. This is largely due to the fact that African Americans face the greatest mortality rates and the lowest survival rate of any racial group when it pertains to the most common cancer types. When compared to their White male counterparts, Black men's overall cancer death rates were $19 \%$ higher when looking at all cancer types [1].

It is important to understand that the dearth of knowledge in the community and prior malpractice history has led to medical mistrust as a major risk factor. Studies have shown that within the quantitative differences in mistrust and CRC screening, African American men have a highlighted sense of fear to experimentation and malpractice [15]. In order to close the gaps in access to care, researchers have focused on methods to increase early screening, through awareness. Studies have shown that decision aids significantly increase cancer knowledge ( $49 \%$ vs. $62 \%$ correct responses) and lessen the conflict of decisional choices, enabling black men to make informed decisions with their providers [16]. Interestingly, study teams that included diverse staff or African American males either as investigators or research staff yield high recruitment results. Those studies tended to employ efforts such as community stakeholder feedback and investment, culturally interesting flyers, face-to-face communication, and flexible times and locations [17].

The use of virtual strategies to engage research participants has increased over the years but during the 2020 COVID Pandemic became a necessity. Two studies that began before the COVID-19 pandemic had incorporated social media and virtual technology to engage and conduct research studies. A $22 \%$ decrease in the number of patients entering clinical trials in the USA was reported by Medidata in August 2020 when compared to pre-COVID rates, and the ability to enroll and recruit patients was reported by 
Table 1 Participant characteristics and engagement strategies

\begin{tabular}{|c|c|c|c|c|}
\hline Study & Study 1 & Study 2 & Study 3 & Study 4 \\
\hline$N(\%$ Black $)$ & $N=229(51)$ & $N=30(100)$ & $N=275(46)$ & $N=178(67)$ \\
\hline $\begin{array}{l}\text { Age, mean } \\
\text { (SD) }\end{array}$ & $54(12)$ & $58(15)$ & $51(17)$ & $55(9)$ \\
\hline \multicolumn{5}{|c|}{ Marital status, $N(\%)$} \\
\hline Married & $74(35)$ & $18(60)$ & $81(30)$ & $76(29)$ \\
\hline Single & $136(65)$ & $12(40)$ & & $102(38)$ \\
\hline \multicolumn{5}{|l|}{$\operatorname{Sex}, N(\%)$} \\
\hline Male & $0(0)$ & $19(63)$ & $85(31)$ & $0(0)$ \\
\hline Female & $229(100)$ & $11(37)$ & $188(68)$ & $178(100)$ \\
\hline Unknown & & & $2(1)$ & \\
\hline \multicolumn{5}{|l|}{ Cancer status } \\
\hline No & $0 \%$ & $57 \%$ & $79 \%$ & $0 \%$ \\
\hline Yes & $100 \%$ & $43 \%$ & $17 \%$ & $100 \%$ \\
\hline \multirow[t]{7}{*}{ Type } & Breast & Prostate & 4\% Missing & Breast \\
\hline & & & $7 \%$ Breast & \\
\hline & & & $2 \% \mathrm{CRC}$ & \\
\hline & & & $1 \%$ Lung & \\
\hline & & & $1 \%$ Blood/hematological & \\
\hline & & & $2 \%$ Prostate & \\
\hline & & & $6 \%$ Other & \\
\hline \multicolumn{5}{|c|}{ Insurance, $N(\%)$} \\
\hline Yes & $229(100)$ & -- & $253(92)$ & $175(66)$ \\
\hline No & $0(0)$ & & $21(8)$ & $3(1)$ \\
\hline $\begin{array}{l}\text { Target } \\
\text { audience }\end{array}$ & $\begin{array}{l}\text { Patients, survivors, } \\
\text { asymptomatic }\end{array}$ & Black males, survivors, families & $\begin{array}{l}\text { Rural residents, community } \\
\text { residents, asymptomatic } \\
\text { individuals, survivors }\end{array}$ & Survivors \\
\hline $\begin{array}{l}\text { Consent } \\
\text { process }\end{array}$ & Written & Verbal & Written or E-consent & E-consent \\
\hline $\begin{array}{l}\text { Community } \\
\text { partners, } \\
\text { type }\end{array}$ & $\begin{array}{l}\text { Civic organizations, } \\
\text { survivor } \\
\text { organizations, other }\end{array}$ & $\begin{array}{l}\text { Community-based organizations, faith-based } \\
\text { organizations, local prostate cancer foundation, } \\
\text { local cancer coalition, local workplace }\end{array}$ & $\begin{array}{l}\text { Cancer coalitions, clinics, } \\
\text { businesses, housing } \\
\text { authorities, government } \\
\text { agencies }\end{array}$ & $\begin{array}{l}\text { Breast cancer } \\
\text { advocate } \\
\text { groups }\end{array}$ \\
\hline $\begin{array}{l}\text { Engagement } \\
\text { strategies }\end{array}$ & $\begin{array}{l}\text { Flyers, posters, } \\
\text { newsletter, radio, } \\
\text { internet, social } \\
\text { media, other }\end{array}$ & Flyers, posters, other & $\begin{array}{l}\text { Community events, radio, } \\
\text { newspaper, social media }\end{array}$ & $\begin{array}{l}\text { Social media } \\
\text { advertise- } \\
\text { ments }\end{array}$ \\
\hline
\end{tabular}

research sites to be significantly affected by the pandemic, with a score of 3.02 out of 5 , where 5 is severely impacted, and 1 is not impacted at all [18]. An online survey in March 2020 representing different research programs found that nearly $60 \%$ of clinical research activities were ceased and stated that remote alternatives to consenting and patient care should be implemented, especially to reduce racerelated participation disparities as most African Americans reside in areas that are disproportionally affected by COVID [19]. A study based on a social media survey found that the method is successful in collecting large-scale data but may be defective in targeting subgroups; African Americans had a lower response rate than the percentage they constitute in the US population, as well as male participants [20], which may indicate the need for the development of a specifically tailored method to target them. Engaging and partnering with cancer advocacy groups is an essential recruitment strategy to reach underserved 
groups. The Y-WE SURVIVE BREAST CANCER study increased online recruitment of Black breast cancer survivor by $41 \%$ after tailored study branding and partnering with breast cancer survivor advocacy groups.

Engaging rural populations in cancer prevention and control research is a priority of the NCI. Despite improvements in cancer prevention and control (CPC), many of the rural communities, including those in Virginia, have higher rates of cancer incidence and/or mortality and receive a cancer diagnosis later than residents in metro localities. The picture of "rural" populations does not often reflect the racial/ ethnic diversity of residents. In many states such as Virginia, African Americas comprise a notable proportion of the population. For example, $62 \%$ of residents in Brunswick county, Virginia (RUCC code = 6) are African American (vs. 32.0\% White). Important strategies were community facing staff who were trusted and options for in-person survey completion. Recruitment of African Americans to cancer research must consider several key components: study team members who identify with participants, culturally competent research, and recruitment sites that community members trust.

Collectively, these studies suggest multiple strategies to reach and engage African Americans in cancer research. The clinical and community samples demonstrate a general interest and willingness of African Americans towards research. Given the current environment of a sensitivity towards issues of social justice and the exacerbation of cancer disparities by the COVID-19 pandemic, practical and innovative strategies are needed to ensure representation of African Americans.

Acknowledgements Research reported in this publication was supported by National Cancer Institute (NCI) R01CA154848 (Sheppard, V.); K99CA256038 (Sutton, A.), P30CA177558 (Edmonds, C.); and the VCU Massey Cancer Center Biostatistics Core Cancer Center Support Grant P30CA016059. It was also supported by the American Cancer Society (ACS) MRSGT-06132-01 CBBPT; P30 CA075292 (Preston, M.).

\section{References}

1. DeSantis CE, Miller KD, Sauer AG, Jemal A, Siegel RL. Cancer statistics for African Americans, 2019. CA Cancer J Clin. 2019;69(3):211-33.
2. Harris Y, Gorelick PB, Samuels P, Bempong I. Why African Americans may not be participating in clinical trials. $J$ Natl Med Assoc. 1996 Oct;88(10):630-4.

3. Owens O, Jackson D, Thomas T, Friedman DB, Hebert JR. African American men's and women's perceptions of clinical trials research: focusing on prostate cancer among a high-risk population in the south. $J$ Health Care Poor Underserved. 2013;24(4):1784-800.

4. Brown DR, Fouad MN, Basen-Engquist K, Tortolero-Luna G. Recruitment and retention of minority women in cancer screening, prevention, and treatment trials. Ann Epidemiol. 2000;10(8 Suppl):S13-21.

5. Hughes TB, Varma VR, Pettigrew C, Albert MS. African Americans and clinical research: evidence concerning barriers and facilitators to participation and recruitment recommendations. Gerontologist. 2017;57(2):348-58.

6. Pariera K, Murphy S, Meng J, McLaughlin ML. Exploring willingness to participate in clinical trials by ethnicity. $J$ Racial and Ethn Disparities. 2017;4(4):763-9.

7. Wujcik D, Wolff SN. Recruitment of African Americans to national oncology clinical trials through a shared resource. $J$ Health Care Poor Underserved. 2010;21(1 Suppl):38-50.

8. Otado J, Kwagyan J, Edwards D, Ukaegbu A, Rockcliffe F, Osafo N. Culturally competent strategies for recruitment and retention of African American populations into clinical trials. Clin Transl Sci. 2015;8(5):460-6.

9. Wallington SF, Dash C, Sheppard VB, Goode TD, Oppong BA, Dodson EE, et al. Enrolling minority and underserved populations in cancer clinical research. Am J Prev Med. 2016;50(1):111-7. https://doi.org/10.1016/j. amepre.2015.07.036.

10. Alizadeh S, Chavan M. Cultural competence dimensions and outcomes: a systematic review of the literature. Health Soc Care Community. 2016;24(6):e117-30. https://doi. org/10.1111/hsc.12293.

11. Luebbert R, Perez A. Barriers to clinical research participations among African Americans. J Transcult Nurs. 2016;27(5):456-63.

12. Edmonds MC, Sutton AL, Cummings Y, Sheppard VB. Opportunities to improve women's health: engaging racial/ ethnic diverse women to provide biospecimens for research. $J$ Women's Health. 2021; https://doi.org/10.1089 /jwh.2020.8502.

13. Sheppard VB, Isaacs C, Luta G, Willey SC, Boisvert M, Harper FWK, et al. Narrowing racial gaps in breast cancer chemotherapy initiation: the role of the patient-provider relationship. Breast Cancer Res Treat. 2013;139:207-16.

14. U.S. Cancer Statistics Working Group. U.S. Cancer Statistics Data Visualizations Tool, based on 2019 submission data (1999-2017): U.S. Department of Health and Human Services, Centers for Disease Control and Prevention and National Cancer Institute; www.cdc. gov/cancer/dataviz, released in June 2020.

15. Adams LB, Richmond J, Corbie-Smith G, Powell W. Medical mistrust and colorectal cancer screening among African Americans: a systematic review. J Community Health. 2017;42(5):1044-61. https://doi.org/10.1007 /s10900-017-0339-2.

16. Allen JD, Reich A, Cuevas AG, Ladin K. Preparing African American men to make informed prostate cancer screening decisions: development and pilot testing of an interactive 
online decision aid. JMIR MHealth Uhealth. 2020;8(5): e15502. https://doi.org/10.2196/15502.

17. Davis SN, Govindaraju S, Jackson B, Williams KR, Christy SM, Vadaparampil ST, et al. Recruitment techniques and strategies in a community-based colorectal cancer screening study of men and women of African Ancestry. Nurs Res. 2018;67(3):212-21. https://doi.org/10.1097 /NNR.0000000000000274.

18. Medidata. COVID-19 and clinical trials: the Medidata perspective. Release 9.0 Accessed March 9, 2021. https://www. medidata.com/wp-content/uploads/2020/09/COVID19Response9.0 Clinical-Trials 2020921 v2.pdf

19. Waterhouse $\bar{D} M$, Harvey RD, Hurley $\bar{P}$, Levit LA, Kim ES, Klepin HD, et al. Early impact of COVID-19 on the of oncology clinical trials and long-term opportunities for transformation: findings from an American Society of Clinical Oncology Survey. JCO Oncol Pract. 2020;16(7): 417-21. https://doi.org/10.1200/op.20.00275.

20. Ali SH, Foreman J, Capasso A, Jones AM, Tozan Y, DiClemente RJ. Social media as a recruitment platform for a nationwide online survey of COVID-19 knowledge, beliefs, and practices in the United States: methodology and feasibility analysis. BMC Med Res Methodol. 2020;20(1): 116. https://doi.org/10.1186/s12874-020-01011-0.

Publisher's Note Springer Nature remains neutral with regard to jurisdictional claims in published maps and institutional affiliations. 